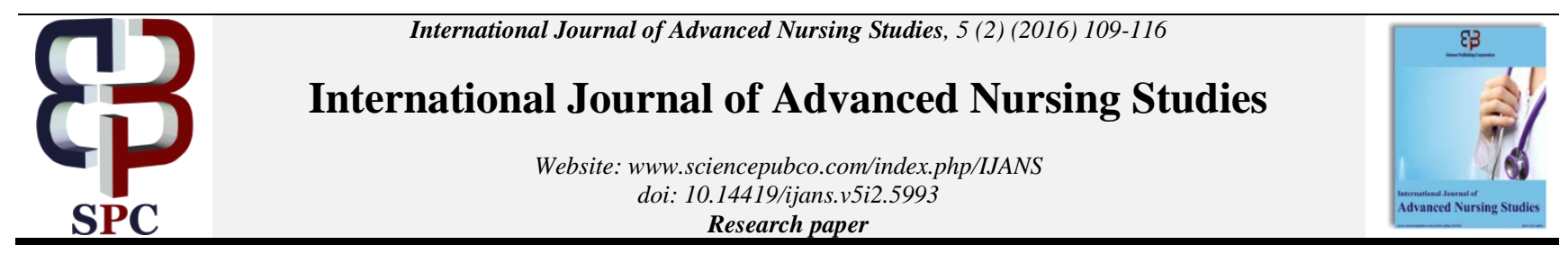

\title{
Relationship between learning style and readiness for self-directed learning among nursing students at king Saud university, Saudi Arabia
}

\author{
Nesreen E. AbuAssi ${ }^{1 *}$, Hanan A. Ezzat Alkorashy ${ }^{2,3}$ \\ ${ }^{1}$ DHN, Day Care Unit, King Abdul Aziz University Hospital, Jeddah, Saudi Arabia \\ ${ }^{2}$ Assistant Professor, Nursing Administration Department, Faculty of Nursing, Alexandria University, Egypt \\ ${ }^{3}$ Nursing Administration \& Education Dept., College of Nursing, King Saud University, Saudi Arabia \\ *Corresponding author E-mail:abuassinesreen@gmail.com
}

\begin{abstract}
Self-directed learning and other prevalent learning styles are important aspects of nursing education because they help nurse educators to predict differences in learners' needs, abilities, and interests. Moreover, nurse educators depend on these predictors when they choose the most suitable teaching strategies, which enable them to manage adult learners effectively. This study's objective is to explore the relationship between learning styles and the willingness to adopt self-directed learning among nursing students in King Saud University (KSU). Using a cross-sectional descriptive correlational design, the study was conducted with 230 undergraduate nursing students (female and male) from the third to eighth academic levels at the College of Nursing at KSU, Saudi Arabia. Kolb's learning styles inventory and the self-directed learning readiness scale were adopted to determine the effects of the self-directed learning approach. The study's findings suggested that the majority of nursing students had a "Diverging" style of learning. The "self-control" subscale was used to determine the willingness for self-directed learning. It recorded the highest mean score compared to the subscales of "self-management" and "desire for learning." However, no statistically significant association was found between learning styles and self-directed learning readiness. Additionally, the findings showed that the majority of the students who participated in this study had little interest in the selfdirected learning approach. Thus, this study recommends that the nursing faculty needs to assess students for their preferred learning style and readiness for self-directed learning before and throughout the students' enrollment in the college. Further, the nursing faculty should apply a variety of teaching methods to manage students' learning needs effectively.
\end{abstract}

Keywords: Learning Styles; Nursing Education; Nursing Students; Self-Directed Learning; Self-Directed Learning Readiness.

\section{Introduction}

For many decades, research has been conducted on the learning styles used by students. The results of this research have shown that effective learning skills should be incorporated and an environment promoting active learning among students should be established. Hence, educators should be capable of assessing the learning skills of students so that their needs and abilities can be determined. The assessment of the learning needs of students enables the teaching faculty to tailor their teaching styles appropriately (Wetzig 2004). Learning style is defined as "the manner in which, and the conditions under which, learners most efficiently and effectively perceive, process, store, and recall what they are attempting to learn" (Slater, Lujan \& DiCarlo 2007).

Self-directed learning (SDL) leads to the development of the skills necessary to meet the challenges associated with modern worldwide systems. For example, the application of SDL in the study of economics provides students with the ability to determine their learning needs based on the situational and professional characteristics of their chosen field. This kind of learning is different from conventional learning methods because it helps to develop the skills needed for continuous professional education (Siminică \& Traistaru 2013).
Modern education systems require the application of learning to the personal and professional lives of students. SDL provides students with the self-confidence to apply gained knowledge to their lives and the surrounding environment. Professionals who are skilled in SDL are capable of solving problems during their daily activities through evidence-based research. SDL enables students to work on areas in which they are the weakest. The abilities to self-monitor and self-assess are developed through SDL, which has been found to be necessary to develop professional competence (Siminică \& Traistaru 2013).

Nursing educators should be trained appropriately to comprehend the learning needs and cognitive abilities of their students. A welltrained nursing educator could improve the learning environment by promoting the use of research-based learning strategies (Wilson 2012).

SDL is the most commonly used method in adult learning practices (Avdal 2013) because it shifts the control of the learning paradigm to the students. Self-directed learners enjoy the freedom to learn what they view as important for themselves. In SDL, students have control over their learning strategies according to their attitudes, abilities, and interests (Fisher, King \& Tague 2001, p. 44). Hence, SDL can be defined as "the process of deciding what to learn, to what depth and breadth; it occurs in a social context and includes decision-making and meta-cognitive thinking abilities" (Shankar, Bajracharya, Jha, Gurung, Ansari \& Thapa 2011). 
A central theme in adult education, SDL, is considered to be associated with the management of lifelong learning for better outcomes. Certain learning situations help to strengthen SDL. Nursing science is changing rapidly, and there is always a need for an information explosion; therefore, it is important to train nurses to be ready for SDL while they are still in the academic stage (Gyawali, Jauhari, Shankar, Saha \& Ahmad 2011).

\subsection{Problem statement}

It is evident that the changing scenario of nursing education caused by advanced nursing practices is promoting the importance of SDL. It has been suggested that SDL promotes the necessary skills and expertise among nurses to meet the challenges of an advanced healthcare environment. Hence, it is necessary for nurse educators to understand the concept of SDL in order to develop the competencies required for active learning among their nursing students (O'Shea 2003).

By using different methods, the readiness to learn can be developed in nursing students through the appropriate assessment of their learning needs. These assessment methods include informal conversations, case studies, focus groups, self-administered questions, pre-tests, and observations (Moyer \&Wittmann-Price 2008). Although the learning directions provided by the teaching faculty at King Saud University (KSU) ensure student-centered education, the education process in the College of Nursing at KSU continues to rely on the conventional system in which knowledge is transferred by the teachers to the students. In this system, the teachers control the extent of knowledge that is provided to the students in the form of subject materials, textbooks, and reference materials. In conventional teaching methods, the teacher analyzes the subject matter and related concepts and designs the content framework Furthermore, the educator is responsible for synthesizing, constructing, and presenting the subject matter in an easily understandable form to the students in a face-to-face situation (Bin Abdulrahman 2007)

Moreover, various methods can be used to assess the effectiveness of provided knowledge in enhancing student's learning of the subject. These include assessment methods such as test, quizzes, assignments, and project submissions, which are incorporated into the teacher-centered learning approach. In the conventional approach, students are the passive recipients of knowledge and are required to listen, memorize, and repeat the information presented in the classroom setting. Hence, students rely mainly on the information provided during their practice sessions. This traditional approach has long been used in educational institutions (Bin Abdulrahman 2007). The College of Nursing is no exception: it also follows the traditional concept of learning.

The competency of nurse educators could promote enhanced student learning in every part of the curriculum. It should be noted that the excellence of the academic skills of the teaching staff is not the only marker for determining the learning efficiency of students. The effective learning of nursing students is dependent on a variety of factors (Peleg, Biderman, Polaceck, Tandeter \& Scvartzman 2005). In contrast to the teacher-centered approach, student's readiness for SDL is a key supporting factor in adopting this approach (Bin Abdulrahman 2007).

The academic staff at KSU uses various teaching methods according to the nature of the course or the teacher's experience, rather than the learning readiness and learning styles of the students. The current teaching styles of the educators involve the integration of various learning and teaching innovations into the conventional teaching style. It has been shown that the learning capability of students is significantly related to learning preferences, personal flexibility, retention, gender, background clinical education, and academic accomplishments. Thus, the preferred learning style of students is found to influence their readiness for SDL. In SDL, students have to respond to an educational program with the aim of mastering its goals and objectives.

The understanding of learning styles and SDLR by nurse educators will enable the establishment of an educational climate that promotes the use of learner-centered approaches to enhance the learning of nursing students. It has been predicted that the learnercentered approach can lead to the development of a feeling of shared responsibility for learning among nursing students and can enhance their autonomy in their professional lives. Hence, the factors associated with increasing or decreasing the ability to selflearn should be determined in order to stimulate SDL among nurses. Kolb's theory of learning is particularly significant for promoting adult learning: it defines skills for active, interactive learning and SDL. According to the theory, all learners are self-directed (El-Gilany \& Abusaad 2013).

The author of the current study demonstrate the learning styles and SDL readiness strategies applied at the KSU College of Nursing. It should be noted that the learning skills of the nursing students at KSU have not been studied previously.

\subsection{Aim of the study}

This study was conducted to assess the effect of learning approaches on the phenomenon of SDL among the nursing students of KSU.

\section{Methodology}

\subsection{Research design}

A cross-sectional correlational descriptive design was used to describe the variables and examine the relationships among these variables.

\subsection{Study settings}

The study was conducted at both male and female campuses of the College of Nursing at KSU, Riyadh, in Saudi Arabia.

\subsection{Participants}

Non-probability convenience sampling was used to select the participants for this study. All nursing students (male and female) enrolled in the Bachelor's (undergraduate) program in levels three to eight in the selected setting were invited to participate in the study. Students who were available at the time of data collection were enrolled in the study $(n=230)$.

\subsection{Instruments}

Two instruments were adopted for the questionnaire: the learning style inventory (LSI) and the SDLR scale. In addition, selected sociodemographic characteristics of the study participants were added. It was assumed that students would not easily understand the questionnaire in English; therefore, it was translated into Arabic language. The questionnaire consisted of three parts:

\subsubsection{Part I: Demographic characteristics}

This part included five questions on the selected demographic characteristics of the participants: gender, age, academic level, marital status, and living status, that is, with family or in KSU campus housing.

\subsubsection{Part II: Learning styles inventory}

This part, which was initially developed (Kolb 1984), revised, and validated by Kolb (2005), comprised 12 questions/statements. For each question/statement, there were four descriptive response statements arranged from 4 (the most dominant learning style) to 1 (the least dominant style). These response statements measured the participants' learning style for later classification into CE, RO, $\mathrm{AC}$, or $\mathrm{AE}$.

Kolb's learning cycle (version 3.1). The questionnaires were designed in accordance with Kolb's learning cycle, which is an evi- 
dence-based learning system. Kolb's learning system consists of the following: $\mathrm{CE}$, feelings; $\mathrm{RO}$, watching; $\mathrm{AC}$, thinking; and $\mathrm{AE}$ doing. In their responses, the participants chose a number from 1 to 4 according to the scale described above. The total scores for $\mathrm{CE}, \mathrm{RO}, \mathrm{AC}$, and $\mathrm{AE}$ were determined by adding value in each answer slot by category (El-Gilany \& Abusaad 2013).

Learning style grid (version 3.1). The experience-based learning system uses the combination subscale $\mathrm{AE} / \mathrm{RO}$ and AC/CE. The grid learning style contains two axes and four quadrants. Two lines are drawn, a horizontal line labeled $\mathrm{AE} / \mathrm{RO}$ and a vertical line labeled AC/CE, which create four quadrants. The upper righ quadrant is the Diverging style, the upper left is the Accommodating style, the lower right is the Assimilating style, and the lower left is the Converging style. Thus, the rectangle describes the students' learning styles.

\subsubsection{Part III: Self-directed learning readiness}

This part was obtained, Fisher et al. (2001), revised and validated by Fisher and King (2010). This scale was initially developed to assist nurse educators in determining the attitudes, abilities, and personal preferences necessary for SDL. The SDL scale consists of 40 items that are grouped under the following three sub-scales: self-management $(n=13)$, desire for learning $(n=12)$, and selfcontrol $(n=15)$. The participants' responses were based on a 5 point Likert scale ranging from $1=$ strongly disagree to $5=$ strongly agree. The responses constituted a range of 40 to 200 on the score scale, which reflected a strong readiness for self-learning among the nursing students.

A cover page was created by the researcher, which included an introduction of the researcher's credentials, the purpose of the study, the selection of participants, process of data collection, and the intended results (Dunn 2005).

\subsection{Ethical considerations}

In the first step of the study, written approval was obtained from the administrative personnel at the College of Nursing at KSU for the participation of both males and females. In the second step, permission was obtained from the authors of the instruments (Kolb's LSI and Fisher et al.'s SDLR scale) to translate them into Arabic and to utilize them in the current study. The study parameters adhered to the ethical codes of conduct for the entire study population. All information collected from the participants was anonymous and confidential. The nursing students provided verbal consent for their active participation in the study. Data were collected from the participants through the distributed questionnaire. The process of data collection took place over a period of twelve weeks from February 2013 to May 2013.

\subsection{Methods of data collection}

To ensure a consistent understanding of the assessment tools by the participants, both surveys (LSI and SDLR scale) were forward-translated from English to Arabic by the researcher using translation and back translation techniques (Maneesriwongul \& Dixon 2014). Then, five of six experts from the College of Nursing at KSU checked each item on the instruments and provided feedback. To ensure the reliability and applicability of the instruments, a pilot study was carried out with 33 nursing students (female $n=24$, male $n=9, \pm 10 \%$ ) who were enrolled in levels three to eight.

Cronbach's alpha was used to confirm the reliability of the Arabic version of the LSI. The highest reliability was for CE $(\alpha=0.661)$, followed by RO $(\alpha=0.685)$, and $\mathrm{AE}(\alpha=0.555)$. The AC was recorded as the least reliable $(\alpha=0.42)$.

Cronbach's coefficient alpha was used to assess the reliability of the Arabic version of the SDLR scale $(\alpha=0.786)$ and the total item pool $(\mathrm{n}=40)$. The self-control subscale $(15$ items $)$ and selfmanagement (12 items) had reliability values of $\alpha=0.835$ and $\alpha=$ 0.790 , respectively, whereas the desire for learning was less relia- ble $(\alpha=0.326)$. The results showed that the study instrument was highly reliable in all sections $(\geq 0.7)$.

Based on the results of the pilot study, the clarity and reliability of the questionnaires were assured, and no modifications were required for any item. Furthermore, during the data collection, the participants did not encounter problems in understanding the questions or in making their responses. The estimated time taken by the study participants to complete the questionnaire was between 15 and 20 minutes.

\subsection{Methods of data analysis}

The data were then analyzed using the Statistical Package for the Social Sciences, version 21. Descriptive and inferential statistical analyses were used to evaluate the findings of this study. A descriptive analysis was used to find the frequency and percentages of the selected demographic characteristics and to describe the participants' preferred learning styles. A chi-square test was used to assess the relationship between learning styles and selected demographic characteristics. A t-test was used in the inferential analysis to compare the groups, and an ANOVA was applied to compare the extent of the relationships between more than two groups.

\section{Results}

\subsection{Response rate}

Three hundred questionnaires were distributed among female students $(\mathrm{n}=150)$ and male students $(\mathrm{n}=150)$. The number of returned sheets was 254 (a response rate of $84.7 \%$ ). All questionnaires were checked for completion and validation. Twenty-four sheets were excluded because they were incomplete and/or invalid; the remaining $230(76.7 \%)$ questionnaires were used in the data analysis.

\subsection{Descriptive statistics}

Table 1 presents the selected demographic characteristics of the participants. The total number of participants in this study was 230. The five selected demographic characteristics were age, gender, academic level, marital status, and residence. More than half of the participants were in the $21 \geq 22$ age group (53.04\%) with an average age of $(22.14 \pm 1.55)$ years. More than half of the participants were male $(51.3 \%)$. about one third of the participants were enrolled in educational level eight (30\%). Most participants were single $(82.6 \%)$ and living with their families.

As shown in Table 2, the preferred learning styles reported by the participants, were diverging (43.9), followed by assimilating (26.5). The styles of accommodating and converging had the same frequency $(14.8 \%)$. Some characteristics, such as gender, academic level, and marital status were statistically significantly associated with learning style.

With regard to the readiness for self-directed learning to the selected characteristics of the participants, the highest mean score of SDLR was self-control $(56.72 \pm 9.17)$, followed by selfmanagement $(45.90 \pm 6.93)$. Desire for learning had the lowest mean score (45.04 \pm 7.32 ). Additionally, a significant association was found between the selected demographic characteristics and SDLR. The results presented in Table 3 show that age group $(\mathrm{P}=$ $.008)$ and academic level $(\mathrm{P}=.01)$ were the only selected demographic variables that showed a statistically significant association with students' readiness for SDL. As shown in Table 3, no statistically significant association was found between learning styles and self-directed learning readiness subscales and the overall score for SDLR.

Table 4 shows the level of readiness for SDL among participants $(n=230)$. More than half of the participants $(52.6 \%)$ had a low level of self-directed readiness for learning, compared to those with a high level of readiness for SDL (47.4\%). The results shown 
in Table 4 show participants' levels of readiness for SDL based on their selected demographic characteristics. No statistically significant association was found between the level of SDLR and students' characteristics except the gender variable $\left(\chi^{2}=0.036, \mathrm{P}=\right.$ 4.38).
Moreover, a comparison was made between the levels of readiness for SDL and the learning styles of the participants. No statistically significant variation was found between both variables $\left(\chi^{2}=2.55\right.$, $\mathrm{P}=0.47)$ (Table 4).

Table 1: Selected Demographic Characteristics of Nursing Students Participants

\begin{tabular}{|c|c|c|}
\hline Variables & $\begin{array}{l}\text { Participants }(n=230) \\
\text { f }\end{array}$ & $\%$ \\
\hline \multicolumn{3}{|l|}{ Age } \\
\hline$\leq 20$ & 30 & 13.04 \\
\hline $21 \geq 22$ & 122 & 53.04 \\
\hline $22+$ & 78 & 33.92 \\
\hline $\mathrm{X} \pm \mathrm{SD}$ & $22.14 \pm 1.55$ & \\
\hline \multicolumn{3}{|l|}{ Gender } \\
\hline Male & 118 & 51.3 \\
\hline Female & 112 & 48.7 \\
\hline \multicolumn{3}{|l|}{ Academic Level } \\
\hline 3rd level & 12 & 5.2 \\
\hline 4th level & 26 & 11.3 \\
\hline 5th level & 42 & 18.3 \\
\hline 6 th level & 27 & 11.7 \\
\hline 7 th level & 54 & 23.5 \\
\hline 8th level & 69 & 30 \\
\hline \multicolumn{3}{|l|}{ Marital Status } \\
\hline Single & 190 & 82.6 \\
\hline Married & 40 & 17.4 \\
\hline \multicolumn{3}{|l|}{ Living } \\
\hline With Family & 216 & 93.9 \\
\hline Housing Campus & 14 & 6.1 \\
\hline
\end{tabular}

Table 2: Learning Styles of Nursing Students Distributed by Selected Characteristics

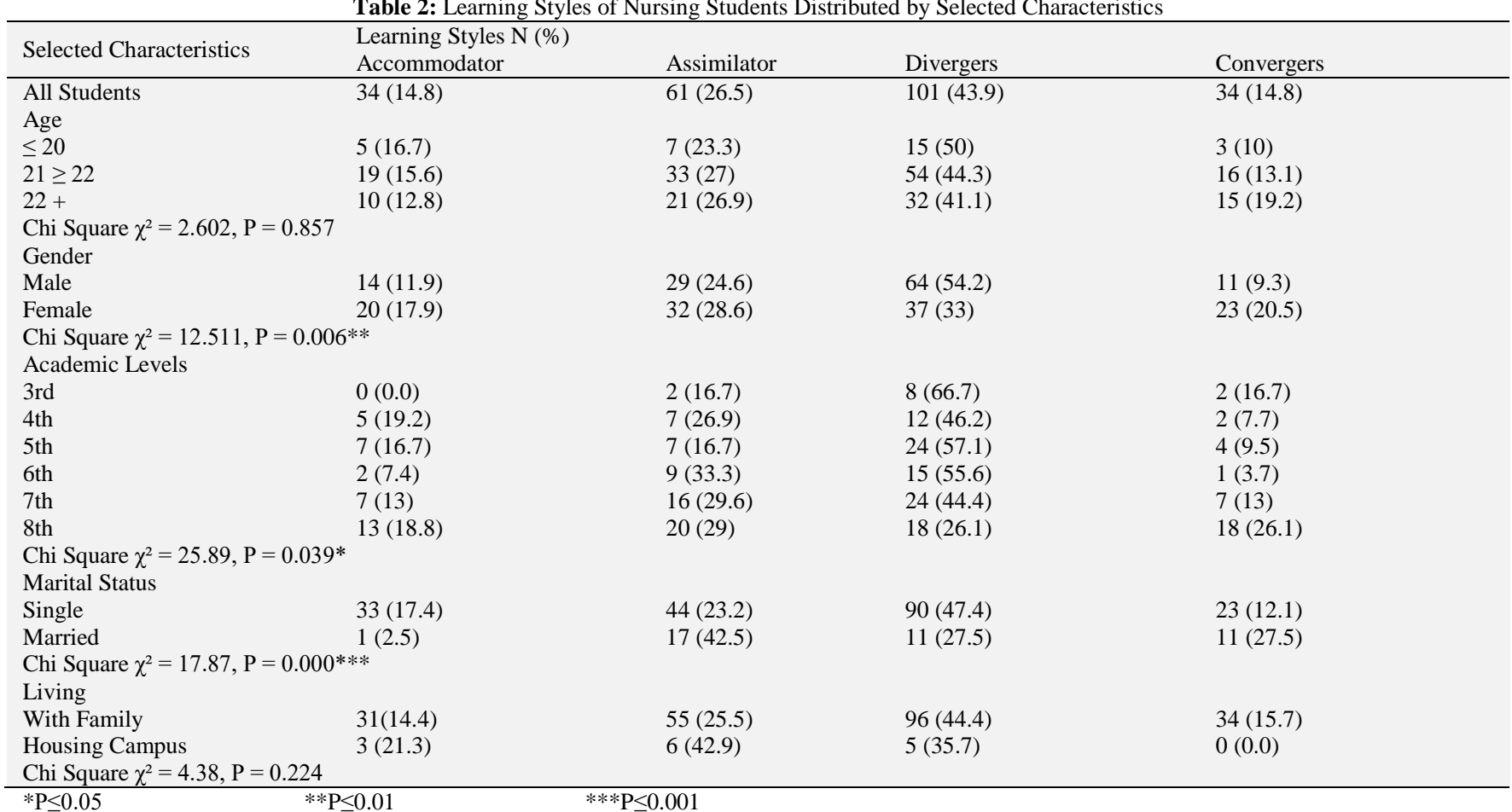

Chi Square $\chi^{2}=4.38, \mathrm{P}=0.224$

Table 3: Self-Directed Learning Readiness Scores of Nursing Students Distributed by Selected Characteristics and Learning Styles

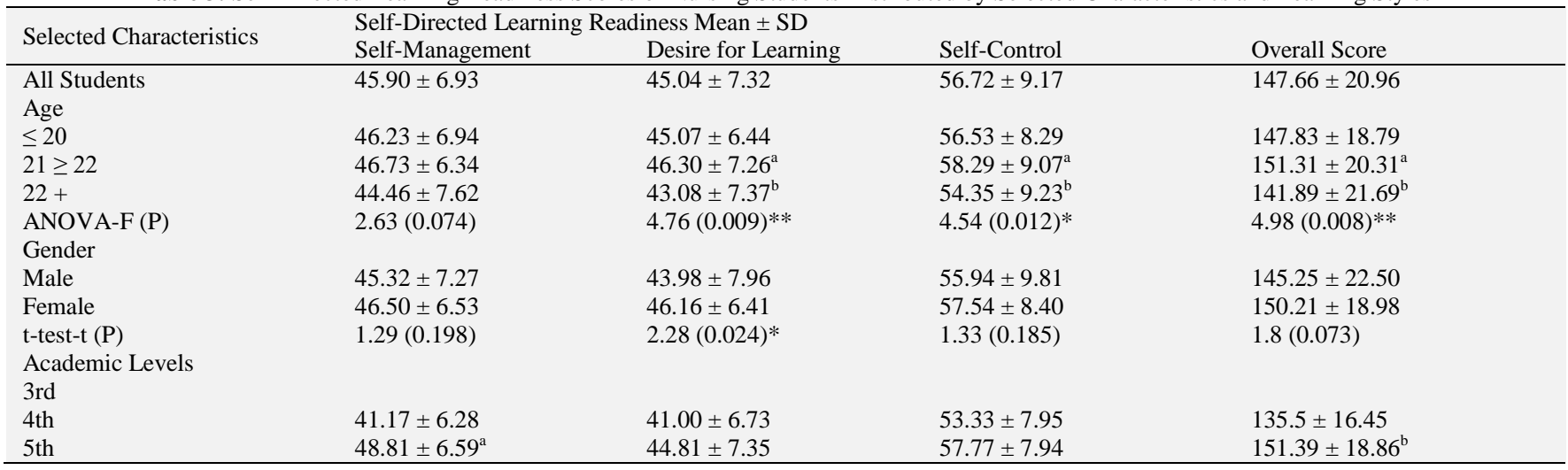




\begin{tabular}{|c|c|c|c|c|}
\hline 6th & $44.26 \pm 7.65$ & $42.26 \pm 8.65$ & $54.14 \pm 10.72$ & $140.67 \pm 24.55$ \\
\hline 7 th & $45.30 \pm 8.37$ & $46.78 \pm 7.11^{\mathrm{a}}$ & $56.63 \pm 9.99$ & $148.70 \pm 23.62$ \\
\hline \multirow[t]{2}{*}{8 th } & $45.74 \pm 6.82^{\mathrm{b}}$ & $44.72 \pm 8.21$ & $55.76 \pm 10.42$ & $146.22 \pm 23.42$ \\
\hline & $46.97 \pm 5.54^{\mathrm{a}}$ & $47.10 \pm 4.78^{\mathrm{a}}$ & $59.28 \pm 6.61^{\mathrm{a}}$ & $153.35 \pm 14.30^{\mathrm{a}}$ \\
\hline ANOVA-F (P) & $3.012(0.012)^{*}$ & $3.56(0.004)^{* *}$ & $2.31(0.045)^{*}$ & $3.13(0.01)^{* *}$ \\
\hline \multicolumn{5}{|l|}{ Marital Status } \\
\hline Single & $45.71 \pm 6.88$ & $44.81 \pm 7.53$ & $30.75 \pm 4.90$ & $56.48 \pm 9.22$ \\
\hline Married & $46.78 \pm 7.16$ & $46.15 \pm 6.14$ & $33.68 \pm 4.13$ & $57.85 \pm 8.95$ \\
\hline t-test-t (P) & $0.88(0.38)$ & $1.05(0.29)$ & $3.51(0.001)^{* * *}$ & $1.03(0.3)$ \\
\hline \multicolumn{5}{|l|}{ Living } \\
\hline With Family & $45.96 \pm 6.96$ & $45.19 \pm 7.30$ & $56.86 \pm 9.18$ & $148.01 \pm 21.00$ \\
\hline Housing Campus & $44.93 \pm 6.50$ & $42.79 \pm 7.44$ & $54.57 \pm 9.00$ & $142.29 \pm 20.34$ \\
\hline t-test-t $(\mathrm{P})$ & $0.54(0.59)$ & $1.19(0.23)$ & $0.91(0.37)$ & $0.99(0.32)$ \\
\hline \multicolumn{5}{|l|}{ Learning Styles } \\
\hline Divergers & $45.86 \pm 7.22$ & $44.75 \pm 7.33$ & $57.02 \pm 9.68$ & $147.63 \pm 21.86$ \\
\hline Assimilator & $45.62 \pm 6.57$ & $45.23 \pm 7.24$ & $56.74 \pm 8.38$ & $147.59 \pm 19.09$ \\
\hline Accommodator & $45.82 \pm 5.54$ & $44.18 \pm 6.59$ & $56.18 \pm 8.35$ & $146.18 \pm 18.27$ \\
\hline Converger & $46.56 \pm 8.05$ & $46.44 \pm 8.17$ & $56.35 \pm 10.08$ & $149.35 \pm 24.50$ \\
\hline ANOVA-F (P) & $0.136(0.938)$ & $0.63(0.592)$ & $0.093(0.964)$ & $0.129(0.943)$ \\
\hline
\end{tabular}

${ }^{*} \mathrm{P} \leq 0.05$
${ }^{a}$ means: The first or more effect on self-Directed Learning subscale and overall score.

${ }^{\mathrm{b}}$ means: The second effect on self-Directed Learning subscale and overall score.

Table 4: Level of Readiness for Self-Directed Learning of Nursing Students Distributed By Selected Characteristics and Learning Styles

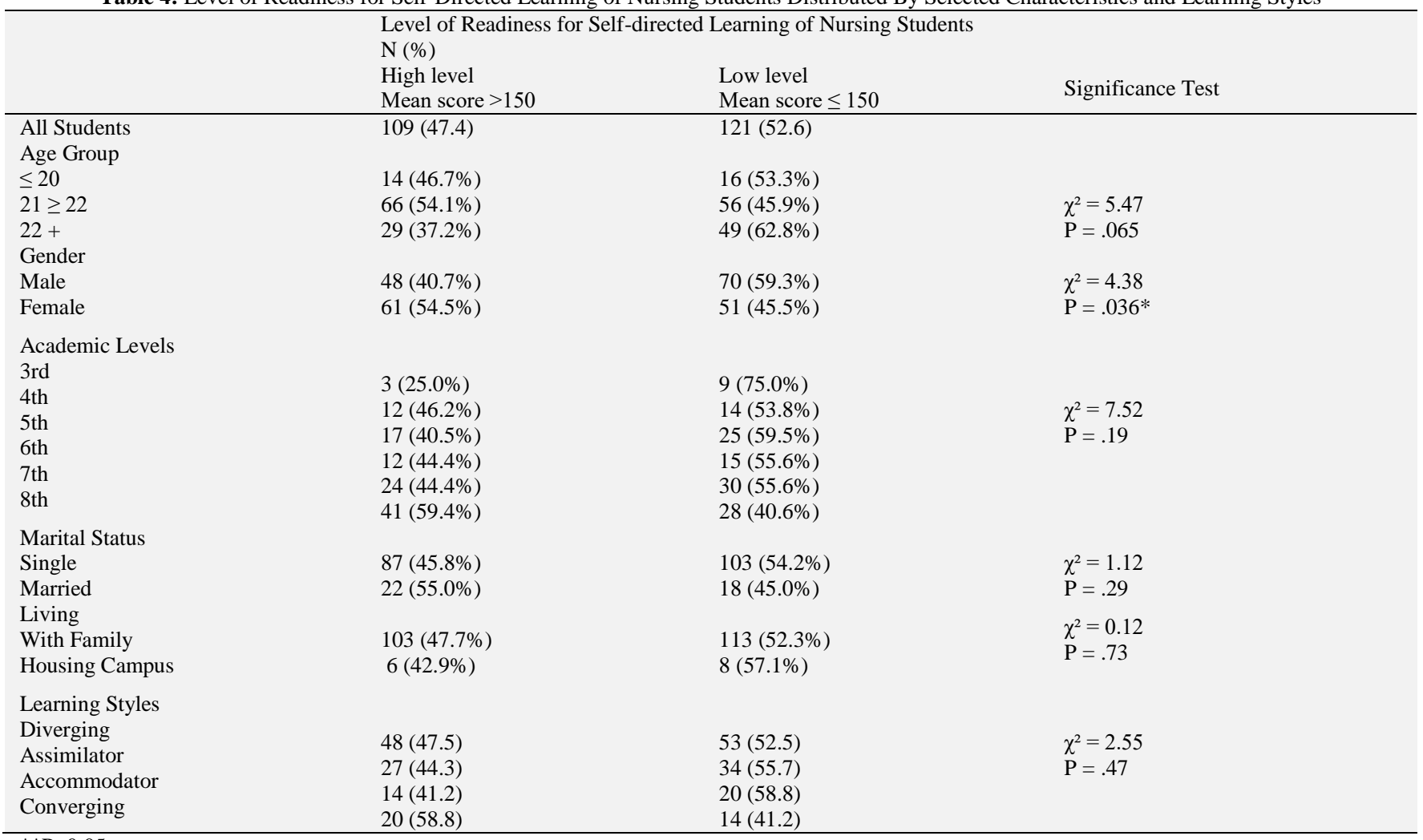

$* * \mathrm{P} \leq 0.05$

\section{Discussion}

The current study was conducted to determine the presence of a relationship between KSU nursing students' learning styles and their level of readiness for SDL. The learning styles and levels of readiness for SDL should be considered as key factors for improving the curriculum and nursing education, and for creating learning opportunities. The findings of the present study support the findings of two previous studies conducted in Australia (Koch et al. 2011) and Turkey (Avdal 2013) on nursing students enrolled in an accelerated graduate course. The academic performance and achievements of the nursing students were compared with changes in the environment of learning and with the teaching style and assessment of the nursing educators.

The present study explored the relationships between learning styles and readiness for SDL among nursing students at KSU. To accomplish the study's goals, many descriptive and inferential variables were implemented to examine and establish whether an association existed between these variables. Moreover, the study attempted to determine whether the selected demographic characteristics of the participants influenced either or both variables. Two hundred and thirty respondents participated in the study. The results of the study are presented and discussed in relation to the responses of the participants.

Overall, the findings of the study revealed that there was no association between the learning styles of the nurse educators and the SDL ability among the nursing students at KSU. In addition, the subscales of SDLR, namely, self-management, desire for learning, and self-control, showed no significant association with learning styles. These findings were similar to the findings of two previous studies conducted in Saudi Arabia and Iran, which concluded that the SDLR score and level had no effect on learning styles (ElGilany \& Abusaad 2013; Safavi et al. 2010).

However, these findings are contrary to a previous study by Linares (1999) conducted in the US, which found that SDLR did affect the learning styles of students. In that study, the Convergers were 
more effective self-directed learners than the other three types of learners (Accommodators, Assimilators, and Divergers). The difference between the current study's findings and those of previous studies may be attributed to the differences in the current educational situation and the students' different learning experiences. The style of education has changed from the dependence on oneway teaching strategies such as lectures and recalling information to interactive techniques, such as discussion, group activities, skill labs, creative and critical thinking, and aggressive progression in the utilization of technology in learning (Linares 1999).

Moreover, the findings showed that the most effective selfdirected learning approach among most nursing students at KSU was the Diverging style. This style relies primarily on the characteristics of CE and RO. The Converging style was the least preferred style. This finding aligns with the findings of two previous studies conducted in Australia and Iran (D'Amore et al., 2012; Salehi \& Shahnooshi 2007), which found that the Diverging style was predominant compared to the Convergent self-directed learning style among nursing students, followed by the Assimilating and Accommodating learning styles.

Many previous studies on this topic reported contrasting results. An American study found that the Converging style was predominant among nursing students, followed by the Assimilating, Accommodating, and Diverging styles (Linares 1999). This finding was supported by two studies conducted in Saudi Arabia (ElGilany \& Abusaad 2013) and Jordan (Suliman 2003). The current study's findings could be attributed to the fact that the learners using the Diverging style could solve problems through imagination and emotion. Furthermore, according to Kolb (1984), these kinds of learners learn through sensitivity, group work, and listening with an open mind.

With regard to SDLR, the current findings showed that selfcontrol was a highly reported subscale for examining the readiness level for self-directed learning among nursing students at KSU. This finding is similar to the findings of many previous studies conducted in Saudi Arabia (El-Gilany \& Abusaad 2013), China (Yuan et al. 2012), and Australia (Fisher et al. 2001, p. 56), which showed that the self-control subscale was reflected by the readiness for SDL.

In contrast, the results of the current study indicate that the subscales of self-management, desire for learning, and self-control, as well as the overall score of SDLR, were slightly lower than those reported in a previous study conducted at Aljouf University in Saudi Arabia (El-Gilany \& Abusaad 2013). However, the present study's results were identical to those reported in previous studies conducted in China (Yuan et al. 2012, p. 427) and Australia (Fisher et al. 2001). However, the current study's findings did not align with those in the Jordanian study (Abu-Moghli et al. 2005), which found that nursing students were perceived as independent learners, and the majority of the students indicated a desire to learn.

Regarding the levels of SDLR, most of the participants had low levels of SDLR (score $\leq 150)$. In Fisher et al.'s (2001) study, more than 150 participants indicated low levels of SDLR. This finding contradicts the results of many previous studies conducted in Saudi Arabia (El-Gilany \& Abusaad 2013), Thailand (Klunklin et al. 2010), Iran (Safavi et al. 2010), China (Yuan et al. 2012), and the US (Linares 1999), where nursing students were found to have high levels of readiness for SDL.

In line with previous findings, the current study found that the levels of readiness for SDL of nursing students at KSU were low, which affected their learning process. The participants' responses indicated that their lack of time management skills, their moods, values, attitudes, culture, and skills acted as barriers to the management of their self-learning process. The findings showed that these personal influences and the ability of the students affected their level of readiness for SDL. The variation among students in their readiness for SDL might be because of individual demographical differences, which might affect their educational goals, motivation to learn, attitudes towards teaching and teachers, and responses to the classroom and clinical practice environments. Such factors could affect their readiness for SDL as well as their dominant styles of learning (Felder and Brent, 2005; Kim \& McLean 2014). Similarly, according to Yuan et al. (2012) the increased level of SDLR might indicate increased emphasis on self-responsibility and relative independence in clinical practice, thereby helping students to rehearse adult roles and prepare them for the beginning of their nursing careers.

The increased level of SDLR might indicate the sense of responsibility among students and the relative independence in the clinical practice of the students, thereby helping them to rehearse adult roles and prepare for the beginning of their nursing careers. In the same context, some studies in the literature emphasized that the cultural background of the nursing student is also an influencing factor in the development of SDL skills of students. Thus, Saudi culture, with its varying components, could influence nursing education to encourage or perhaps promote SDL (Ahmad \& Majid 2010).

The idea of self-learning has been advocated widely by educational institutions. It has been suggested that the learning process of students could be expedited by enhancing their self-learning skills. However, many supporters of traditional learning systems have asserted that self-directed learning may lead to superior acquisition, which could be disadvantageous to some extent. In order to make a decision about the acceptance of self-directed learning as a standard learning style, evidence-based knowledge should be collected.

The cognitive advantage of SDL is that it allows students to develop the skills of knowledge acquisition. Through SDL, students may be exposed to information that is not readily accessible in teacher-centered, passive learning. Students who are skilled in SDL could encode the information that they find useful but are unable to access through passive learning. Hence, through SDL, students are able to preserve the material that they select based on their needs and interests (Gureckis \& Markant 2012).

A study was conducted on the introduction of SDL to student nurses, who were encouraged to use this approach in an undergraduate research course. It should be noted that SDL acts as a promoter of research-based practice among nursing professionals. The effects of this learning approach were evaluated by checking the knowledge, satisfaction, and readiness of the nurses. The study concluded that the motivation gained by the teaching method helped in achieving appropriate knowledge and satisfaction among the nursing professionals. In light of the study's findings, it is suggested that blended teaching methods are the most appropriate; therefore, student-centered approaches could be applied. Additionally, individual students could choose their learning approach based on their motivation and readiness (Gagnon, Gagnon, Desmartis \& Njoya 2013).

\section{Conclusion}

The findings of the current study showed that the dominant learning style of the majority of nursing students at KSU was the Diverging style. Moreover, the participants' level of readiness for SDL was low although their self-control was high compared to other SDLR subscales. The results showed no significant connection between the participants' learning styles and the variables of their readiness for SDL, which supported the findings of previous research (El-Gilany \& Abusaad 2013; Safavi et al. 2010).

In the sample used in the present study, some demographic characteristics that influenced the learning styles and readiness for SDL were gender, academic level, and marital status, whereas age and academic level influenced SDL ability.

Based on the main findings of this study, the following recommendations for nursing professionals are outlined as follows:

1) Nurse educators should determine whether teaching strategies meet the needs of their students in order to increase the number of professional nurses. The need to retain current and future students is more important now than it was before. The learning needs of future nurses could be met effectively if the teaching strategies were to enhance the stu- 
dents' ability to learn instead of hindering their thought processes.

2) Nursing educators should consider learning styles when planning e-learning courses and activities. Therefore, nurse education styles should be changed to promote learning through a distance learning system, particularly for the BSN degree.

3) Nursing students need to move from traditional educational approaches to more active and independent approaches that emphasize critical thinking, self-direction, and collaboration as central strategies for learning.

4) It is critical that the faculty ensure consistency among al aspects of the curriculum in order to provide consistent opportunities for students to control their learning and increase their input in the learning process. The development of SDL skills seems to be mandatory to enhance this learning approach.

5) There is a need for students and faculty to continually appraise the extent to which opportunities for SDL are provided to students within the context of teaching and learning. This is important because if the faculty overestimates the frequency with which they provide this type of learning experience for students, they may not be aware of the need to increase their efforts, thereby limiting students' development of their SDL readiness. If students underestimate the frequency with which they receive SDL experiences, they may also underestimate their knowledge and skills in this area and hesitate to continue SDL activities after graduation.

\subsection{Limitations of the study}

- The quantitative study was carried out with nursing students in a four-year college at one Saudi university, which was a limited yet diverse population. The single location and the limited number of participants (compared to all nursing students in the target population) may have limited the generalization of the findings to other higher institutions of nursing education.

- Furthermore, both the SDLR and the LSI were self-reporting questionnaires, which carried the risk of subjective bias: that is, one's perception of self may have differed from the perceptions of others.

- The participation of the nursing students was voluntary, which may have affected the validity of the sample.

\subsection{Recommendations for future research}

Based on the findings and limitations of this research study, the following recommendations are offered:

1) Replicate this study using larger samples and sub-samples of the population.

2) Conduct research to include more than one college and/or university in Saudi Arabia in order to generalize the findings to the entire population of the nursing students in Saudi Arabia.

\section{Acknowledgements}

My thanks are due first and foremost to "ALLAH" the Most Merciful and the All-Compassionate, who gave me the strength and ability to complete this work. I would also like to acknowledge Dr. Murray Fisher, University of Sydney, Australia, who gave me permission to adopt and translate the SDLR scale developed by him and other colleagues for collecting data. Further, I wish to convey my deepest thanks to the Hay Group, who gave me permission to adopt and translate the LSI developed by David Kolb. Moreover, I would like to express my great appreciation for Dr. Mona Al-Wakeel, for her assistance in managing the statistical analysis for my study. I would also like to extend my sincere gratitude to King Abdulaziz City for Science and Technology, which gave me the financial support to complete the research. Thanks are also for all faculties, staff members, colleagues, and friends for their support and cooperation during the data collection and research processes.

\section{References}

[1] Abu-Moghli F, Khalaf I, Halabi J \& Wardam, L (2005), Jordanian baccalaureate nursing students' perception of their learning styles. International Nursing Review 52(1), 39-45. http://dx.doi.org/10.1111/j.1466-7657.2004.00235.x.

[2] Ahmad BE \& Majid FA (2010), Self-directed learning and culture: A study on Malay adult learners. Procedia - Social and Behavioral Science 7 , 254-263. http://dx.doi.org/10.1016/i.sbspro.2010.10.036.

[3] Avdal EÜ (2013), the effect of self-directed learning abilities of student nurses on success in Turkey. Nurse Education Today 33(8), 838-841. http://dx.doi.org/10.1016/j.nedt.2012.02.006.

[4] Bin Abdulrahman KA (2007), Students' views on student-teacher relationship: A questionnaire-based study. Journal of Family \& Community Medicine 14 (2), 81-87.

[5] D'Amore A, James S, \& Mitchell EK (2012), Learning styles of first-year undergraduate nursing and midwifery students: A crosssectional survey utilising the Kolb Learning Style Inventory. Nurse Education Today 32(5), 506-515. http://dx.doi.org/10.1016/j.nedt.2011.08.001.

[6] Dunn K (2005), Interviewing. In Qualitative Research Methods in Human Geography (Ha I., Ed.). Oxford University Press, South Melbourne, Australia.

[7] El-Gilany A-H \& Abusaad FES (2013), Self-directed learning readiness and learning styles among Saudi undergraduate nursing students. Nurse Education Today, 33(9), 1040-1044. http://dx.doi.org/10.1016/j.nedt.2012.05.003.

[8] Felder RM \& Brent R (2005), Understanding student differences. Journal of Engineering Education 94(1), 57-72. http://dx.doi.org/10.1002/j.2168-9830.2005.tb00829.x.

[9] Fisher MJ \& King J (2010), The Self-Directed Learning Readiness Scale for nursing education revisited: A confirmatory factor analysis. [Validation Studies]. Nurse Education Today 30(1), 44-48. http://dx.doi.org/10.1016/j.nedt.2009.05.020.

[10] Fisher M, King J \&Tague G (2001), Development of a self-directed learning readiness scale for nursing education. Nurse Education Today 21(7), 516-525. http://dx.doi.org/10.1054/nedt.2001.0589.

[11] Gagnon MP, Gagnon J, Desmartis M \& Njoya, M (2013), the impact of blended teaching on knowledge, satisfaction, and selfdirected learning in nursing undergraduates: A randomized, controlled trial. Nursing Education Perspectives 34(6), 377-382. Available at: http://www.nlnjournal.org/doi/full/10.5480/10-459 http://dx.doi.org/10.5480/10-459.

[12] Gureckis TM \& Markant DB (2012), Self-directed learning: A cognitive and computational perspective. Perspectives Psychological Science, 7(5), http://dx.doi.org/10.1177/1745691612454304

[13] Gyawali S, Jauhari AC, Shankar PR, Saha A \& Ahmad M (2011), Readiness for self-directed learning among first semester students of a medical school in Nepal. Journal of Clinical and Diagnostic Research 5(1), 20-23. Available at http://www.jcdr.net/articles/PDF/1130/1480_E(C)_F(J)_R(S)_PF(A )_P(20-23)_LowRes.pdf

[14] Kim S \& McLean GN (2014), the impact of national culture on informal learning in the workplace. Adult Education Quarterly 64(1), 39-59. http://dx.doi.org/10.1177/0741713613504125.

[15] Klunklin A, Viseskul N, Sripusanapan A \& Turale S. (2010). Readiness for self-directed learning among nursing students in Thailand. Nursing and Health Sciences 12(2), 177-181. http://dx.doi.org/10.1111/j.1442-2018.2010.00515.x.

[16] Koch J, Salamonson Y, Rolley JX, \& Davidson PM (2011), learning preference as a predictor of academic performance in first year accelerated graduate entry nursing students: A prospective followup study. Nurse Education Today 31(6), 611-616. http://dx.doi.org/10.1016/j.nedt.2010.10.019.

[17] Kolb DA (1984), experiential learning: Experience as the source of learning and development. Prentice-Hall, Englewood Cliffs, N.J.

[18] Kolb DA (2005), The Kolb learning style inventory-version 3.1: Self scoring and interpretation booklet. Hay Group Transforming Learning, Boston, MA. Available at: http://www.whitewaterrescue.com/support/pagepics/lsitechmanual.pdf 
[19] Linares AZ (1999), Learning styles of students and faculty in selected health care professions. [Comparative Study]. Journal of Nursing Education 38(9), 407-414. Available at: http://europepmc.org/abstract/MED/10609585

[20] Maneesriwongul W \& Dixon JK (2004), Instrument translation process: A methods review. [Review]. Journal of Advanced Nursing 48(2), 175-186. http://dx.doi.org/10.1111/j.13652648.2004.03185.x

[21] Moyer BA \& Wittmann-Price RA (2008), Nursing education Foundations for practice excellence. F. A. Davis, Philadelphia.

[22] O'Shea E (2003), Self-directed learning in nurse education: A review of the literature. Journal of Advanced Nursing 43(1), 62-70. http://dx.doi.org/10.1046/j.1365-2648.2003.02673.x.

[23] Peleg R, Biderman A, Polaceck Y, Tandeter H \& Scvartzman, P (2005), The family medicine clerkship over the past 10 years at Ben Gurion University of the Negev. International Journal of Teaching and Learning in Medicine 17(3), 258-61. http://dx.doi.org/10.1207/s15328015tlm1703 10

[24] Safavi M, Shooshtari zadeh Sh., Mahmoodi M \&Yarmohammadian M (2010), Self-directed learning readiness and learning styles among nursing students of Isfahan University of Medical Sciences. Iranian Journal of Medical Education 10(1), 27-35.

[25] Salehi S \& Shahnooshi E. (2007). Nursing students' preferred learning style. [Original Article]. Iranian Journal of Nursing and Midwifery Research Autumn 12(4), 153-175.

[26] Shankar R, Bajracharya O, Jha N, Gurung SB, Ansari SR \& Thapa HS (2011). Change in medical students' readiness for self-directed learning after a partially problem-based learning first year curriculum at the KIST medical college in Lalitpur, Nepal. Education for Health (Abingdon) 24(2), 552.

[27] Siminică M \& Traistaru A (2013), Self-directed learning in economic education. International Journal of Education and Research $1,12$.

[28] Slater JA, Lujan HL \& DiCarlo SE (2007), does gender influence learning style preferences of first-year medical students? Advances in Physiology Education 31(4), 336-342. http://dx.doi.org/10.1152/advan.00010.2007.

[29] Suliman WA (2003), the relationship between clinical judgment abilities and learning styles of Jordanian diploma and baccalaureate prepared nurses at hospital settings. Dirasat, Medical and Biologica Sciences, 30(1), 20-29.

[30] Wetzig SM (2004), Learning style preferences and learning strategies in intensive care nurse education. Available at: http://espace.library.uq.edu.au/view/UQ:10348

[31] Wilson ML (2012), Learning styles, instructional strategies, and the question of matching: A literature review. International Journal of Education 4(3), 67-87. http://dx.doi.org/10.5296/ije.v4i3.1785.

[32] Yuan HB, Williams BA, Fang JB \& Pang D (2012), Chinese baccalaureate nursing students' readiness for self-directed learning. Nurse Education Today 32(4), 427-431. http://dx.doi.org/10.1016/j.nedt.2011.03.005 